\title{
DESAIN INDUSTRI REFLEKSI SPIRIT DINAMIKA JAMAN
}

\author{
Baskoro Suryo Banindro \\ Program Studi Desain Produk, FSR ISI Yogyakarta \\ Email: banindro@yahoo.com
}

"je pense, donc je suis" (Descartes)

\begin{abstract}
Industrial design has become a part of visual culture and penetrates all sides of human life. As a scientific discipline, profession, and mass production, its existence has caused the emergence of great industrial designers, monumental industrial products, renewable techniques and materials, fashionable models that can be considered as reality and reflection of an era dynamics. Industrial design has resulted not only mass products but also esthetic styles, streams, and idioms that transformed them into universal trends of design.
\end{abstract}

Keywords: industrial design, representation, spirit of age

\begin{abstract}
ABSTRAK
Desain industri telah menjadi bagian dari budaya visual dan menyeruak di segenap kehidupan manusia. Sebagai sebuah disiplin ilmu, profesi dan produksi massa, sejak kehadirannya telah memunculkan tokoh desain industri yang ulung, produk industri monumental, teknik dan bahan terbarukan, model yang fashionable, yang dapat dipandang sebagai realita dan refleksi dinamika jaman. Desain industri tidak saja memunculkan produk massa, namun juga menjadikan gaya - mashab dan idiom visual yang estetik menjadikannya trend desain yang universal.
\end{abstract}

Kata kunci: Desain Industri, Representasi, Semangat Jaman.

\section{Pendahuluan}

Desain industri sebagai sebuah aktifitas dan profesi merupakan bagian dari disiplin praktik yang lebih umum yaitu desain (Heskett, 1980). Adapun desain itu sendiri adalah profesi yang sudah lama dikenal, para pengrajin telah mengawali dengan membuat objek-objek benda terapan untuk memenuhi kebutuhan akan perkakas. Meskipun desain industri sering dimasukkan dalam industri pada akhir abad kesembilan belas, pembidangan profesi perancang desain industri itu sendiri masih agak kabur, sehingga kegiatan seniman, arsitek, tukang, penemu, insinyur, teknisi dan desainer perusahaan besar, semuanya menggunakan label profesi sebagai desainer produk industri.Kini ketika masuk di awal abad kedua puluh, legitimasi penyandang sebagai perancang desain industri, muncul sebagai profesi yang terintegrasi dan mengakomodasi semua kegiatan yang lebih kompleks, yakni menggabungkan antara teknologi, trend, aspek estetika dan bisnis (Sparke, 1986)

\section{Sejarah Desain Industri}

Desain industri merupakan puncak aktivitas revolusi industri, adapun prosesnya merupakan sinergi antara penciptaan produk (ide) dan proses manufaktur (mekanisasi) yang sudah dimulai pada awal abad ke-16 (Heskett \& Giorgetta, 1980). Menurut Asosiasi Desainer Industri Amerika atau lebih sering dikenal dengan ISDA, desain industri adalah layanan profesional untuk menciptakan dan mengembangkan konsep- 
konsep dan spesifikasi yang mengoptimalkan fungsi, nilai dan penampilan produk dan sistem untuk saling menguntungkan antar pengguna (konsumen) dan produsen (pabrikan/industri) (Industrial Designhttp://www.idsa.org)

Desain industri lahir sebagai akibat dampak pertumbuhan industrialisasi dan mekanisasi yang dimulai dengan munculnya revolusi industri di Inggris pada pertengahan abad ke-18 (Heskett, 1980: 10). Ketika depresi besar mulai pada tahun 1929, sejumlah individu kreatif dari berbagai bidang seni, termasuk teater, iklan, grafis, desain mode dan mebel, merintis profesi baru. Menanggapi "dunia baru" yang belum pernah terjadi sebelumnya dan memenuhi permintaan akan industri "gaya baru", para seniman ini tengah memasuki dunia industri yang mana selama ini lebih populer disebut dengan "era mesin," untuk memperkenalkan hadirnya dunia baru "desain moderen" (McFarland, 2014). Desain industri dipandang sebagai sinergi antara seni terapan dan ilmu pengetahuan, bertujuan menciptakan dan mengembangkan nilai-nilai estetis, ergonomis dan fungsional dalam a r t e f a k y a n g d i p r o d u k s i (http://dx.doi.org/10.5772/54548)

\section{Pionir Desain Industri}

Arsitek Jerman Peter Behrens yang memulai debutnya di tahun 1907, sering dianggap sebagai pionir industrial design, di mana konsep karyanya sangat dipengaruhi oleh desain Inggris abad ke-19 dan dikaitkan dengan penyair William Morris dengan gerakannya tentang seni dan kerajinan (http://www.britannica.com/topic/industrialdesign). Istilah desain industri itu sendiri pertama kali dimuncukan oleh Joseph Claude Sinel pada tahun 1919 (meskipun dalam sebuah wawancara Sinel mengelak akan hal itu), dan segera dikenal luas di akhir dekade tahun itu pula. Sementara itu desainer industri lainnya yakni Christopher Dresser selalu dikenang sebagai "the first independent industrial designer" (Heskett, 1980: 12). William Morris, seorang arsitek, memulai gerakan seni dan kerajinan, merancang kertas dinding (wallpaper) dan tekstil untuk memperkenalkan keindahan ke "ruang hidup". Morris ingin membuat kehidupan orang-orang biasa menjadi lebih elegan dan menyenangkan. Pada tahun 1880, dipengaruhi oleh Ruskin's, mempunyai gagasan bahwa "sukacita" harus jelas ter "tera" dalam setiap produk desain industri. Menurutnya seni tidak hanya untuk sekedar pelengkap, seni tidak hanya diperoleh dari pendidikan, seni adalah kebebasan yang tidak dibatasi.

Karena kurangnya produksi massal, hasil desain industri kala itu masih diterima oleh konsumen dalam skala masih secara terbatas 'Sparke, 1991: 67-70). Seorang arsitek dan desainer terkemuka dunia kelahiran Hungaria, Marcel Breuer (19021981), yang bekerja di sekolah Bauhaus sejak 1920, menghasilkan karya monumental dalam bidang mebel dan eksperimen kursinya yang menjadi identitas modernisme dunia. Pada tahun 1937 bersama Walter Gropius, mendesain beberapa mebel yang menjadi karya penting dalam perkembangan desain modern dunia. Ludwig Mies van der Rohe (1886-1969), tokoh desainer modern dunia terkemuka, menciptakan banyak karya arsitektur di Jerman yang memiliki konsep dan eksperimen alami dengan prinsip desainnya Less is more. Kursi Barcelona hasil karyanya pada tahun 1929 banyak terjual dan menjadi simbol desain modern. Di samping nyaman dipakai, kursi tersebut ringan dan didesain untuk produksi massa.

\section{Produk Desain Industri}

Industrial designer adalah seorang penerjemah yang menghubungkan antara orang marketing dengan orang engineering. Pada prinsipnya industrial design sama 


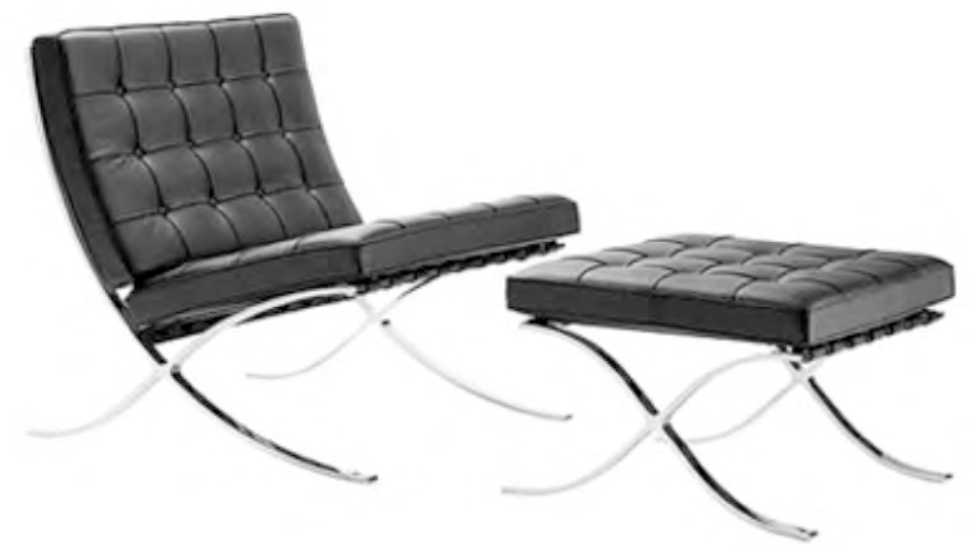

Gambar 1. Kursi Barcelona diproduksi masal dan menjadi tren di eranya. karya Ludwig Mies van der Rohe, simbol desain modern era 30an.

(Sumber: http://www.knoll.com/shop/by-designer/ludwig-mies-van-der-rohe)

dengan product design, bedanya industrial design lebih fokus ke barang mass product seperti barang elektronik, sedangkan product design lebih fokus ke barang home industry (Reindy Allendra, 2014). Pengaturan tentang Desain Industri dikenal pada abad ke-18 terutama di Inggris karena adanya revolusi industri. Desain Industri pada masa itu, awalnya berkembang pada sektor tekstil dan kerajinan tangan yang dibuat secara massal. Aturan ini dibuat untuk membedakan kegiatan desain industri dari desain berbasis kerajinan, dan bentuk produk yang dirancang oleh pencipta produk karena kebutuhan industri Noblet 1993:21).

Desain industri menghasilkan kreasi tentang bentuk, konfigurasi, atau komposisi garis atau warna atau garis dan warna atau gabungannya, berbentuk 2 (dua) atau 3 (tiga) dimensi, yang memberi kesan estetis, dapat dipakai untuk menghasilkan produk, barang, komoditas industri atau kerajinan tangan. Perancang industri melayani konsumen melalui kepekaan (sensitif) dan penemuan (inovatif), kolaborasi antara seni, ilmu pengetahuan, teknik, antropologi, pemasaran, manufaktur, dan ekologi. Perancang desain industri memberi bentuk pada hampir semua produk dalam budaya kita. Mereka mencari kesempatan dan keunggulan melalui identifikasi dan upaya pemecahan masalah. Sehingga dampak dan kontribusi kreatif mereka muncul pada aspek penampilan, nilai fungsi, dan lingkungan. Solusi yang paling inovatif dari objek industrinya, terletak dari apa yang bisa dikenal (be known) dan apa yang mungkin (maybe) mewujud pada hasil produknya.

Desain industri selalu diawali oleh serangkaian proses desain yang rancangannya dapat diterapkan untuk produk-produk yang akan dibuat melalui teknik produksi massal (Heskett 1980). Dalam bukunya "Design for the real World", Papanek menjelaskan ada 6 (enam) tata kelola desain: pertama adalah metode yang dibagi menjadi 2 (dua) yaitu Episteme dan Techne. Episteme adalah pengetahuan yang melibatkan daya serap, imajinasi, dan abstraksi. Techne adalah keteknikan atau keterampilan bertukang. Kedua adalah asosiasi yang berarti kemampuan menghubungkan antara gagasan dengan kemampuan panca-indra dengan menggunakan gambar, bagan, dan 
sebagainya. Asosiasi terlebih dahulu diawali dengan kegiatan mengidentifikasikan kebutuhan dari produk yang akan dibuat, perencanaan fisik berupa merancang model (desain) dari karya yang akan dihasilkan. Selanjutnya mengevaluasi kualitas dari produk yang telah dibuat.

Ketiga adalah estetika, yang berarti berhubungan dengan keindahan, sehingga dapat memadukan seluruh unsur yang ada dalam penciptaan dan hasil atas karya yang dirancang. Keempat adalah kebutuhan, yang berarti sesuatu yang diperlukan untuk membuat karya, dalam hal ini dapat ditinjau dari alasan mengapa produk itu dibuat dan dari aspek materialnya apa yang tepat digunakan guna mewujudkan rancangan tersebut. Kelima adalah telesis yang berarti fungsi desain yang berusaha mewadahi dimensi sosial dan budaya pada tempat desain tersebut dibutuhkan dan digunakan. Keenam adalah kegunaan yang berarti fungsi dari sebuah karya harus tepat guna dan tepat sasaran artinya nilai fungsi dan penggunaannya sesuai dengan rancangan dan rencana mengapa projek itu yang telah dipilih (Papanek, 1971:78).

\section{Desain Produk dan Semangat Jaman}

Tokoh desain dunia Frank Lloyd Wright menyatakan sikap positif terhadap usahausaha mekanisasi dan menolak penghujatan terhadap dunia permesinan yang dianggap merusak etika bentuk, meskipun penampilan luar dan bentuk produk konsumsi massal, aspek fungsi dan kerja mekanik, sebelumnya tidak dianggap sebagai produk seni. Baginya, mesin adalah alat tak berakal dan hakikatnya bukan merupakan sumber kerusakan di muka bumi. Dengan teknologi permesinan manusia mejadi semakin mudah menyingkap kenyataan alam dan keindahan material. Raymond Loewy, seorang desainer produk terkemuka dunia lainnya, dikenal sebagai perintis profesi desain produk industri. Pada tahun 1909 ia mulai mendesain model pesawat sebagai inspirasi penerbangan perdana Santos-Dumonts. (Sabtu, 21 Maret 2015Tokoh-Tokoh Desainer Dunia.html)

Sebagai produk budaya visual, desain industri telah dan seharusnya dapat merefleksikan kondisi jaman dan merepresentasikannya ke dalam wujud produk masal. Lompatan besar teknologi, penemuan bahan/material baik itu plastik, aluminium, resin, kevlar telah menghasilkan serangkaian produk fabrikasi moderen yang sangat kontras dengan produk masal era masa $1 \mathrm{a} l \mathrm{u}$ dan it u menjadikannya memorabiliasouvenir semangat jamannya (zeitgeist). Saat pertama kali kendaran Jeep diciptakan Amerika, semata-mata guna memenuhi kebutuhan alat angkut untuk mematahkan supremasi Kubelwagen yang menjadi sarana transportasi tentara Jerman. Bentuk, teknologi dan estetika yang ada hari ini, telah banyak mengalami pergeseran dengan model Jeep generasi pasca perang.

Desain industri telah mengubah fungsi praktis power utility dan multy purpose ke tuntutan jaman yang lebih estetik, fashionable dan memiliki inner beauty. Demikian pula yang terjadi pada desain industri Piaggio dari Italia, telah menciptakan alat transpotasi personal scotter yang pada awalnya memanfaatkan limbah sisa perkakas perang dunia ke II menjadi alat transpotasi semi otomatis di jamannya. Kini Vespa sebagai sebuah merek hasil desain industri telah menjadi benda artefak yang amat legendaris dan menjadi ikon anak muda modern serta simbol next generation di abad milenium ini. 

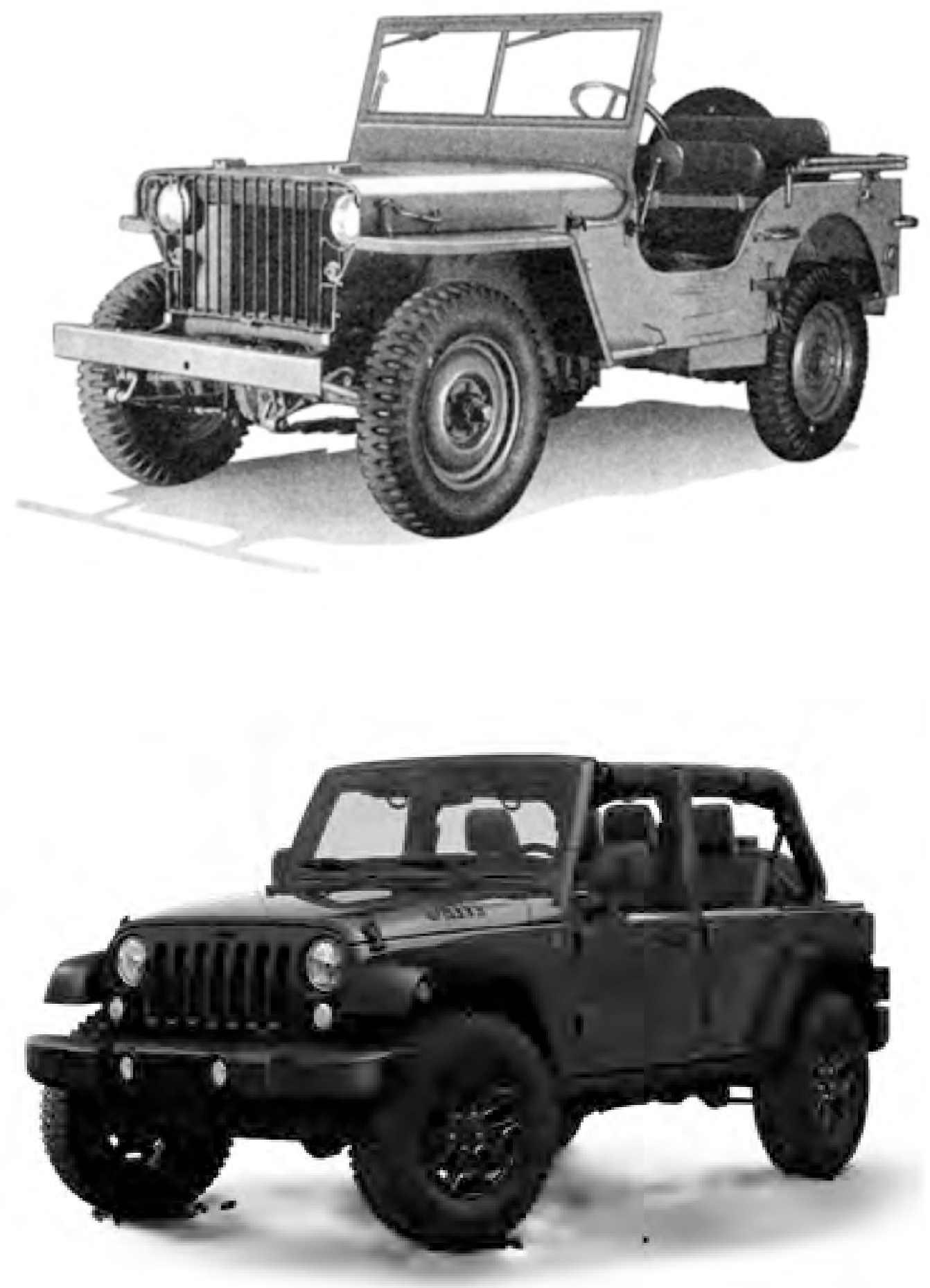

Gambar 2. Willys MB 1941 dan Willys Wheeler 2014, sama fungsi beda estetika, masing-masing mewakili semangat jamannya.

(Sumber: http://www.netcarshow.com/jeep/1943-willys_mb) 

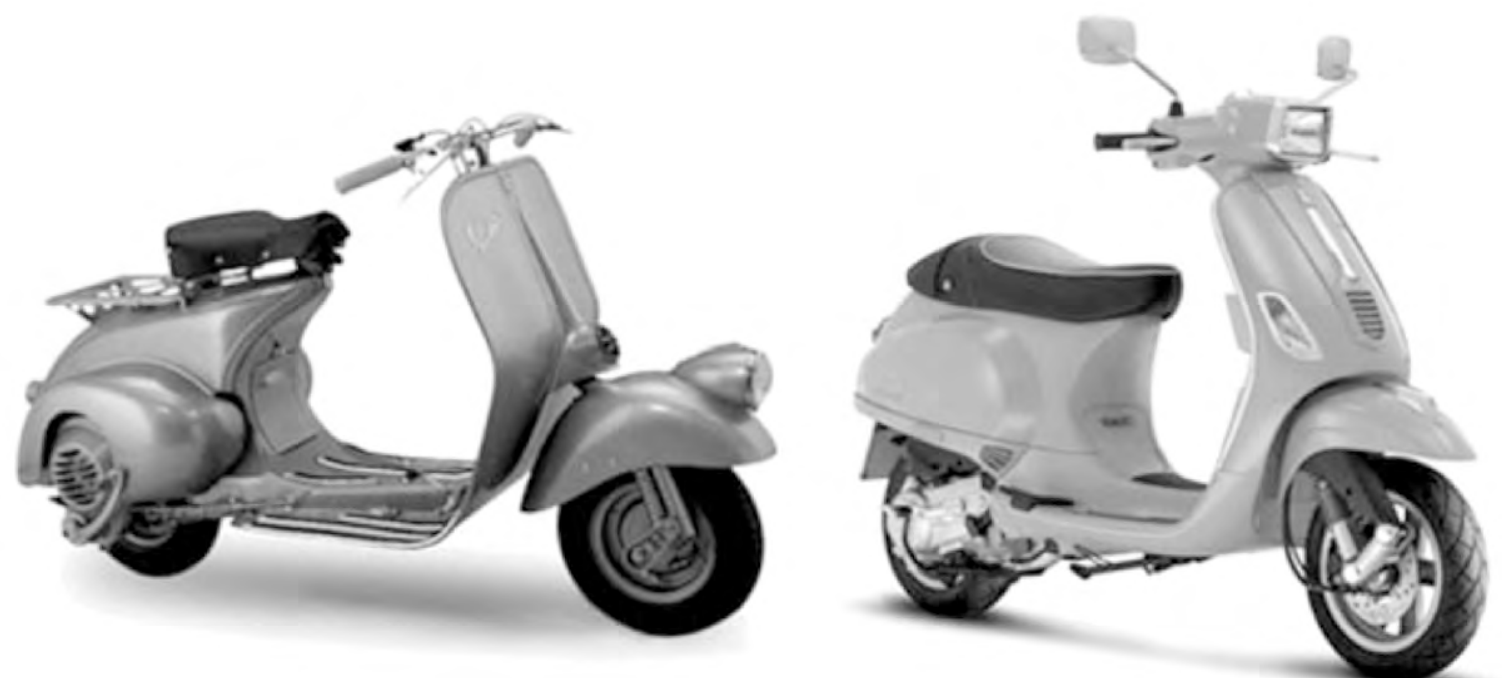

Gambar 3. Scooter Vespa awal dan model saat ini, menampakkan spirit di masanya. (Sumber: https://www. vespa+piaggio+old+and+new+vespa)

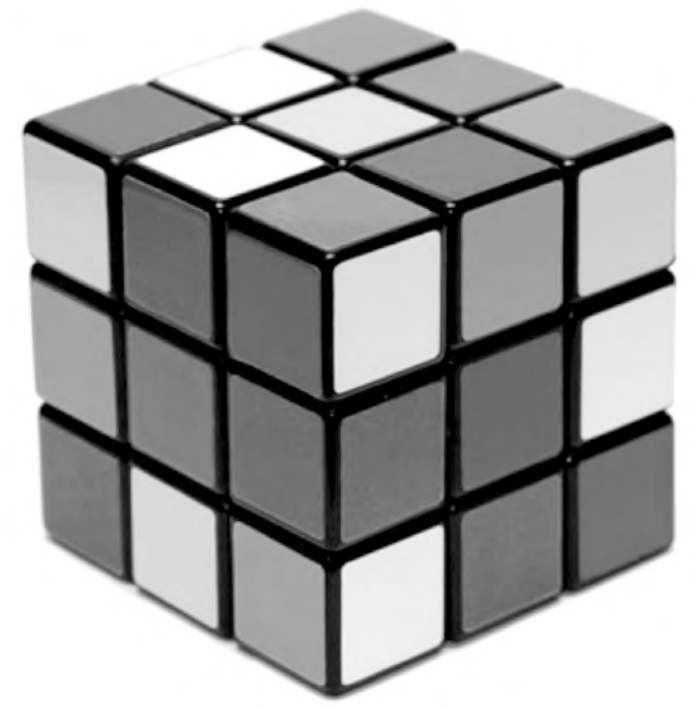

Gambar 4. Rubik-cubesalah satu hasil desain industri mainan, menjadikannya benda memorabilia souvenir sepanjang masa.

(Sumber: https://www.rubiks.com)

Desain produk dapat dihasilkan melalui kegiatan manufaktur (manufactured product) yaitu suatu cabang industri yang mengaplikasikan mesin, peralatan dan tenaga kerja dan suatu medium proses untuk mengubah bahan mentah menjadi barang jadi untuk dijual. Bisa juga merupakan hasil pabrikan (fabricated product) yakni pembuatan barang dengan standar tertentu secara besar-besaran di pabrik atau merupakan hasil besar industrialisasi (industrialized product) yang merupakan bagian dari proses modernisasi dimana dalam produksinya terkait dengan inovasi dan sarat teknologi. Integrated circuit (IC), chip, laser, personal computer (PC), light emitting diode (LED) telah menjadi ikon peradaban hasil kebudayaan pada masanya. Produk masal peradaban itu bisa dilihat pada munculnya industri skala besar seperti Concorde, Rubik- 


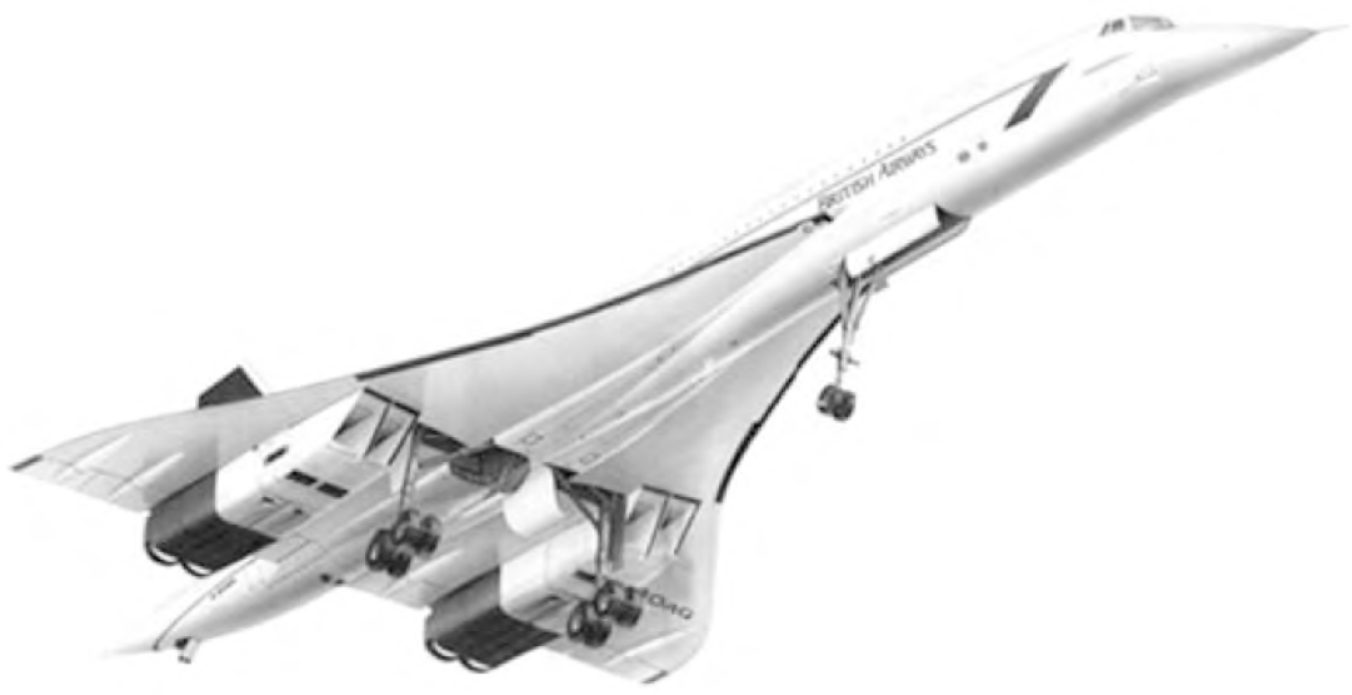

Gambar 5. Pesawat Concorde mewakili era supersonic hasil teknologi Perancis dan Inggris, dirancang Pierre Satre dan Sir Archibald Russell 1969,simbol pencapaian budaya abad 19 (Sumber: British Airways Concorde G-BOAC)
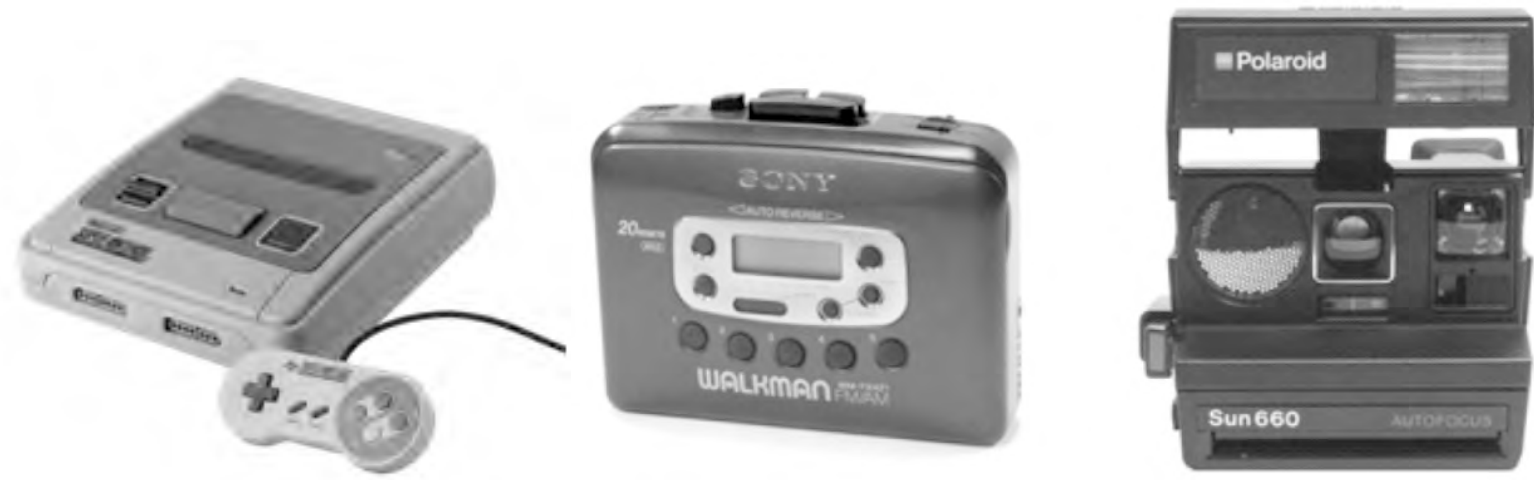

Gambar 6.Nintendo, walkman, polaroid masing-masing mewakili desain industri elektronika di masanya.

(Sumber: www.eurogamer.net)

cube, Nintendo, walkman, radiopager, smartphone, WiFi, dll.

Semangat jaman (zeitgeist) merupakan pemikiran dominan pada suatu masa yang menggambarkan dan mempengaruhi sebuah budaya dalam masa itu sendiri (Saarinen, 2006). Dalam dimensi ruang dan waktu, semangat jaman menghasilkan suatu gaya atau mashab yang dikemudian hari menjadi dominan dan disebut-sebut sebagai pelopor gaya. Zeitgeist merupakan pemicu dari modernisme dan sesuatu yang dapat menumbuhkan pemikiran orisinal dan berhasrat akan intelegensi (Magee, 2011, p.262) 


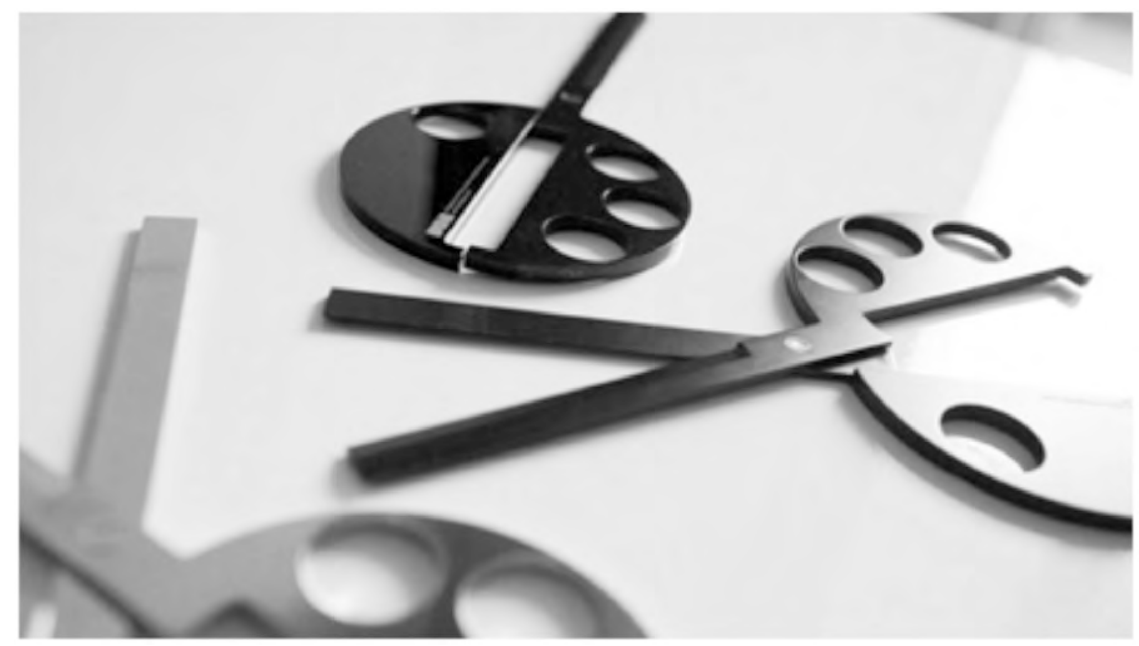

Gambar 7. Gunting matematika adalah paradigma untuk gunting baru masa kini dapat digunakan sehari-hari, dipadu kombinasi dengan golden ratio matematika dan sentuhan estetika.

(Sumber: http://designspiration.net/image/9573685160589)

\section{Desain Industri Kini dan Masa Depan}

Menurut Vossoughi, president dan pemilik "Ziba Industries", tantangan bagi desainer produk industri adalah untuk dapat membawa empati dan kepekaan bagi hasil pekerjaan mereka (www.ziba.html). Subjek desain industri adalah seni dan sejarah desain yang menghubungkan masa lalu dengan visi masa depan. Desain produk hari ini jarang yang hanya memperhatikan unsur fisik, tetapi lebih mengedepankan harapan konsumen bahwa untuk produk kiranya lebih dapat bermakna dan memberikan pengalaman lebih besar daripada produk yang dihasilkan oleh industri sebelumnya. Suatu tuntutan keahlian nyata seorang desainer produk adalah, kemampuan mereka untuk dapat mengidentifikasi akan kebutuhan dan kondisi jaman, menciptakan makna dan bentuk serta paradigma produk kekinian, juga mengenai apa yang akan harus dilakukan dan mengapa hal itu yang diwujudkan, menjadi tanggung jawab dan koreksi kritis para desainer industrial desain di masa kini (http //www.Industrial Design.html). Desain produk terutama secara formal, bertanggung jawab untuk bersama-sama menjaga dan menghasilkan kualitas produk yang fungsional, sehingga tidak semata bersifat estetik. Perkembangan desain industri dalam memasuki milenium ketiga, setidaknya telah menunjukkan lompatan besar rancang gaya dan mode yang sangat kontras, seksi dan futuristik. Hal ini bisa dilihat dari lahirnya model-model terbaru produk desain industri dengan citra fisik yang inovatif, microdigital, nirkabel, serba otomatis.

Munculnya eksposisi, eksplorasi, kompetisi, riset dan transformasi budaya yang mengglobal semakin mendorong perkembangan daya gagas desainer industrial mencapai ke arah itu. Sebagai salah satu contoh di sini adalah lahirnya rancangan VW New Beetle karya desainer industri Indonesia Chris Lesmana. Untuk mendesain mobil ini, Chris bekerja sama dengan desainer eksterior, Frank Bruse. Mobil hasil rancangan Chris yang sekarang tinggal di Jerman ini sudah diluncurkan di Amerika Serikat beberapa waktu lalu dan dia menyebutnya sebagai mobil impian.

Di tangan Chris, mobil VW Kodok seri 2012 ini kembali dilahirkan untuk menjadi mobil populer dan legendaris dengan cara 
mempercantik atap yang dibuat lebih rendah, roda yang lebih besar dan interior yang kompak dan sporty. Desain mobil VW Beetle itu sendiri terpilih sebagai kompetisi World Car of The Year pada New York International Auto Show 2012. (zulkifli19.wordpress.com)

Konsep pesawat terbang futuristik yang diselenggarakan oleh KLM Aircraft Concept Design Competition, mendorong para desainer industri untuk menghasilkan karya yang benar-benar novelty dan spektakuler. Rancangan pesawat KLM WB-1010terpilih, merupakan hasil rancangan Reindy Allenda, seorang Industrial designer asal Jakarta, yang memenangkan konsep pesawat terbang untuk delapan puluh lima tahun ke depan. Bila ditilik dari rekayasa visual, maka jelas terlihat bagaimana sosok produk objeknya mengadopsi bentuk-bentuk alam, mimesis dari satwa laut terbesar si paus biru.
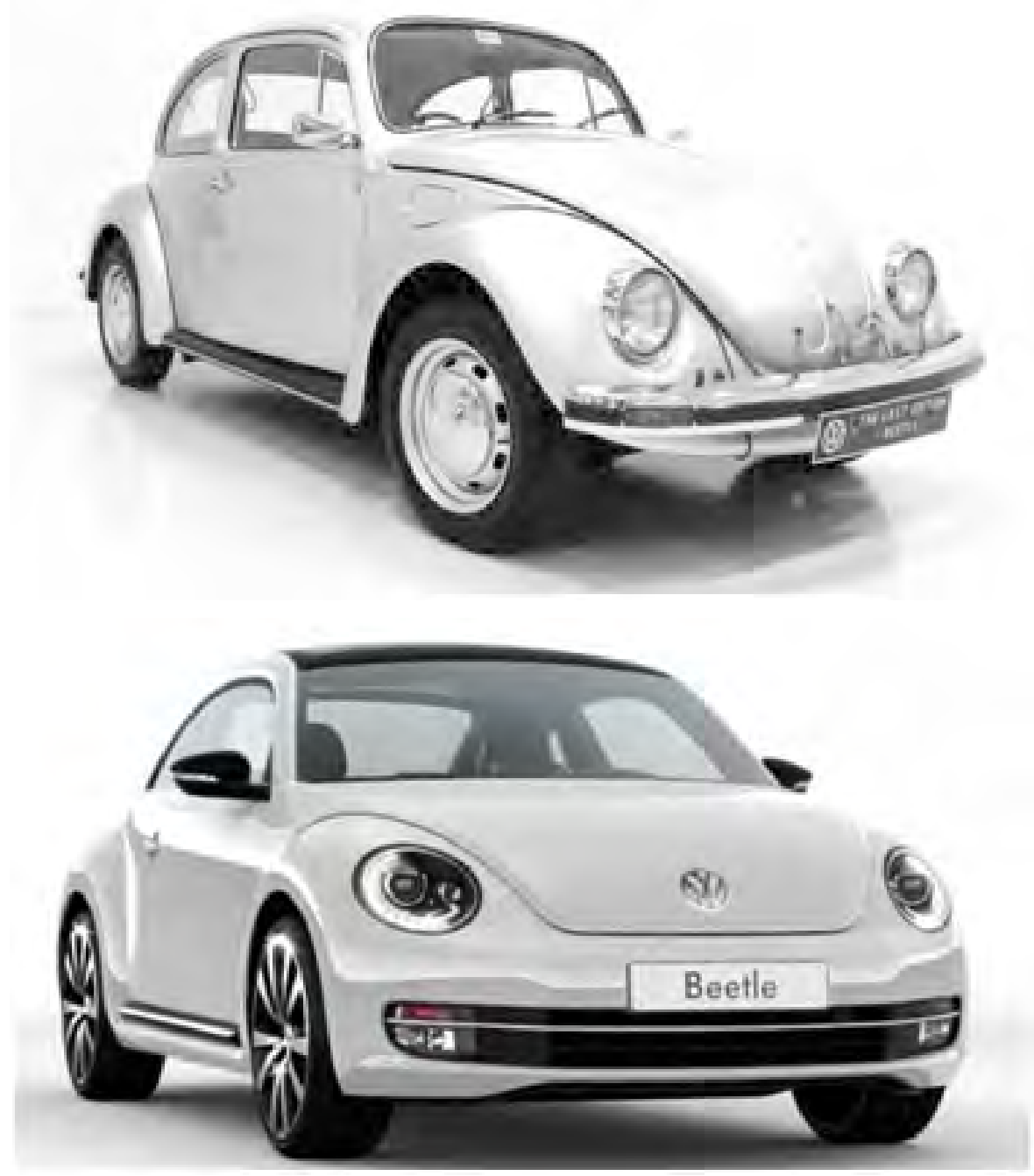

Gambar 8. Volkswagen era Porsche, dirancang untuk kebutuhan keluarga, New Beetle, dirancang untuk segmen wanita sehingga bentuk mobil dipadupadankan dengan kesan seksi dan sporty. (Sumber: otomotif.news.viva.co.id) 


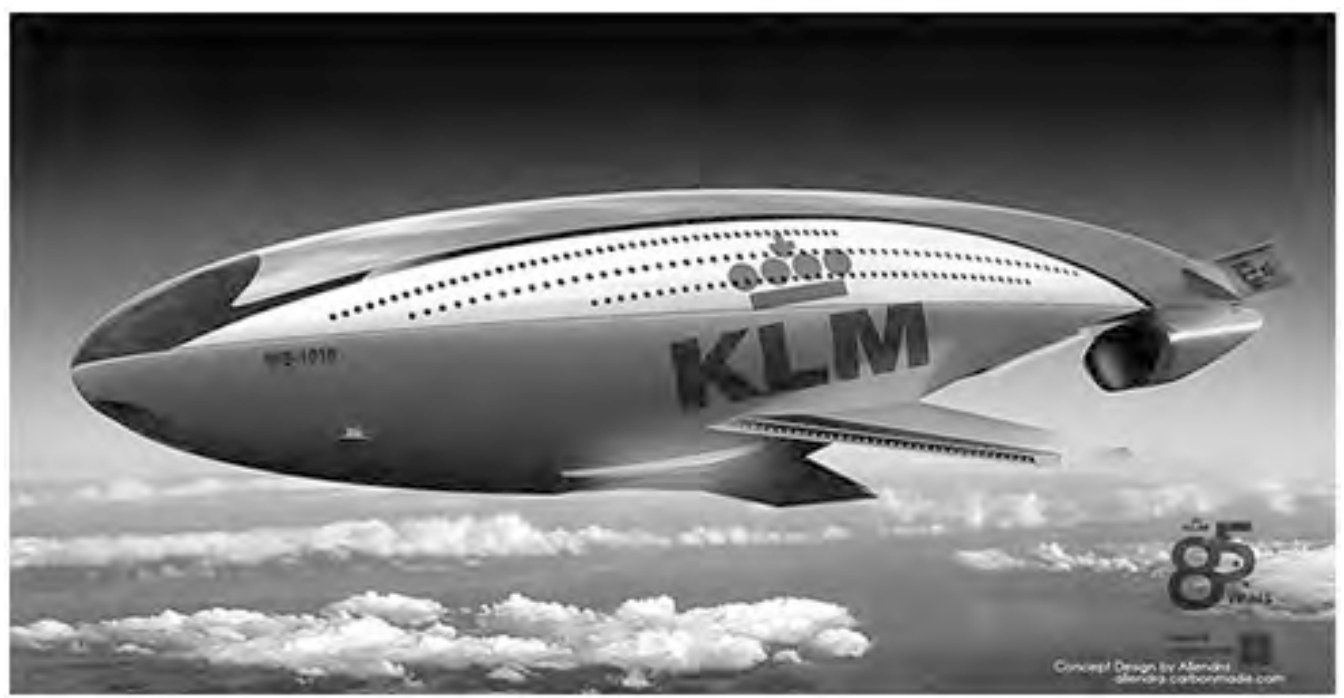

Gambar 9. Desain pesawat terbang Reindy Allenda sangat berani, futuristik dan spektakuler. (Sumber: http://www.coroflot.com/allendra)

\section{Penutup}

Desain industri harus dapat memeuhi kebutuhan antara tuntutan ekonomi (keuntungan dan pemasaran), teknik (mekanik dan rekayasa produksi), seni (estetika dan desain visual) dan budaya (karsa dan rasa), sehingga harus dapat menghasilkan invensi prototip dan cetak biru yang terbarukan.Mengutip Irvan Noe'man desainer industri futuristik mengatakan bahwa desain juga merupakan sebuah produk budaya yang harus bisa menjadi penanda zaman. Kehadirannya mewakili dan menjadi salah satu penanda sejarah bergulirnya generasi.

Secara umum gaya zaman adalah suatu cara ekspresi atau sikap estetik yang khas dan unik pada suatu karya seni yang muncul karena teknik penciptaan, konsep visual, atau estetikanya. Gaya desain bisa memberi petunjuk mengenai suatu masa atau periode tertentu, suatu tempat atau negara tertentu, atau suatu aliran pemikiran atau mashab tertentu.

\section{Daftar Pustaka}

Heskett (1980). Industrial Design (World of Art Series) Industrial Design. World of Art. London: Thames \& Hudson.
Heskett \& Giorgetta (1980).Industrial design and Industrial Designers Society of America

I.B. Kashim, Visual and Material Culture in the Context of Industrial Design: The Contemporary Nigerian Experience, Department of Industrial Design, Federal University of Technology, Akure, Nigeria

Magee, Glenn Alexander (2011). "Zeitgeist". Continuum International Publishing Group.

McFarland, (2014) Founders of American Industrial Design

Noblet, Jocelyn de (1993). Design in Progress." In Noblet, Jocelyn de. Industrial design: reflection of a century. Paris: Flammarion/APCI

Papanek, Victor (1971). Design for the Real World: Human Ecology and Social Change, New York, Pantheon Books

Sparke, Penny, (1986). An introduction to design and culture in the twentieth century.

Sparke, Penny, (1991) Design in Context, London: Bloomsbury

Saarinen, Eero (2006). Shaping the Future. Yale University Press 
Tautan:

Ivan Noe'man, vivalife Empat Pakem dalam Mendesain Furnitur, liputan Lutfi Dwi Puji Astuti, Tasya Paramitha Senin, 16 Maret 2015, 15:54 WIB

I n d u s t ria 1 D e s i g n / h t t p : //www.britannica.com/topic/industrialdesign Industrial Design/http://www.htlferlach.at/en/our-education/industrial-design 